\title{
Diagnostic and clinical considerations in prolonged grief disorder
}

\author{
Maercker, Andreas ; Lalor, John
}

\begin{abstract}
This review focuses on the similarities and differences between prolonged grief disorder (PGD) and post-traumatic stress disorder (PTSD). It highlights how a PTSD-related understanding aids the investigation and clinical management of PGD. Grief has long been understood as a natural response to bereavement, as serious psychological and physiological stress has been regarded as a potential outcome of extreme or traumatic stress. PTSD was first included in DSM-III in 1980. In the mid-1980s, the first systematic investigation began into whether there is an extreme or pathological form of mourning. Meanwhile, there is much research literature on complicated, traumatic, or prolonged grief This literature is reviewed in this article, with the following questions: Is it possible to distinguish normal from nonnormal grief? Which clinical presentation does PGD have-and how does this compare with PTSD? Finally, diagnostic, preventive, and therapeutic approaches and existing tools are presented.
\end{abstract}

Posted at the Zurich Open Repository and Archive, University of Zurich ZORA URL: https://doi.org/10.5167/uzh-63530

Journal Article

Published Version

Originally published at:

Maercker, Andreas; Lalor, John (2012). Diagnostic and clinical considerations in prolonged grief disorder. Dialogues in Clinical Neuroscience, 14(2):167-176. 


\section{Clinical research}

\section{Diagnostic and clinical considerations in prolonged grief disorder}

Andreas Maercker, MD, PhD; John Lalor, MSc

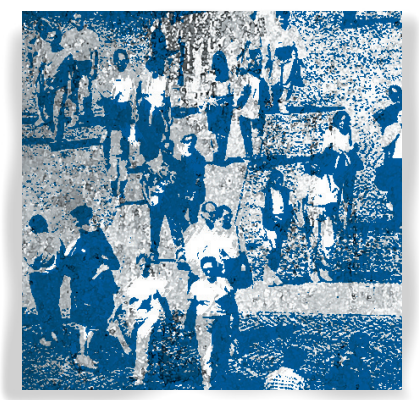

This review focuses on the similarities and differences between prolonged grief disorder (PGD) and post-traumatic stress disorder (PTSD). It highlights how a PTSDrelated understanding aids the investigation and clinical management of PGD. Grief has long been understood as a natural response to bereavement, as serious psychological and physiological stress has been regarded as a potential outcome of extreme or traumatic stress. PTSD was first included in DSM-III in 1980. In the mid-1980s, the first systematic investigation began into whether there is an extreme or pathological form of mourning. Meanwhile, there is much research literature on complicated, traumatic, or prolonged grief. This literature is reviewed in this article, with the following questions: Is it possible to distinguish normal from non-normal grief? Which clinical presentation does PGD have-and how does this compare with PTSD? Finally, diagnostic, preventive, and therapeutic approaches and existing tools are presented.

(c) 2012, LLS SAS

Dialogues Clin Neurosci. 2012;14:167-176.

Keywords: bereavement; prolonged grief disorder; complicated grief; pathological grief; post-traumatic stress disorder; stress response disorder
Introduction

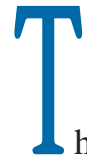

he issue of the existence or nonexistence of a condition, disease, or disorder related to bereavement has been debated over the last two decades with increasing intensity. On the one hand, psychiatrist authors or researchers affiliated with psychiatric hospitals dealing with the more severe mental disorders tend to challenge the need for a new bereavement-related mental disorder. On the other hand, authors and scientists primarily connected with psychiatric outpatient care, or practitioners in the community, see evidence of, and need for, a well-defined condition or disorder in some cases of grief.

We use the example of a 42-year-old woman whose 19year-old son had committed suicide by train impact over a year previously. The woman reported that there had been no warning whatsoever. While she knew her son to be an introvert, she did not suspect him of being suicidal. She was thus immensely shocked by his death. Although she had not witnessed the collision herself, she kept imagining the scene vividly after the tragedy. This was so painful that she decided to take part in our outpatient trauma therapy program. ${ }^{1}$

This patient did not fulfil the criteria for "classic" posttraumatic stress disorder (PTSD-in particular, criteria

Author affiliations: Division of Psychopathology and Clinical Intervention, University of Zurich, Switzerland

Address for correspondence: Andreas Maercker, MD, PhD, Chair \& Director, Psychopathology \& Clinical Intervention, University of Zurich, Binzmuhlestr. 14/17, $\mathrm{CH}-8050$ Zurich, Switzerland

(e-mail: maercker@psychologie.uzh.ch) 


\section{Clinical research}

A1 and A2). However, based on a clinical assessment, we decided to provide her with a form of therapy very similar to that used for PTSD. In this article, we will discuss theoretical and conceptual issues of prolonged grief disorder (PGD), as well as issues pertaining to assessment and treatment of patients suffering from this disorder.

\section{Pioneers in establishing a prolonged grief disorder diagnosis}

The history of a bereavement-related disorder could be said to have begun with the Book of Job in the Hebrew Bible, around 300 years before Christ. Job exhibits severe and prolonged desperation about the sudden loss of his sons and daughters, whereupon he asks, "Why did I not perish at birth, and die as I came from the womb?" (Job 3:11). Sigmund Freud, the discoverer of the many parts of the psychological apparatus and subtle psychological functions, dedicated one of his best known opuses to "Mourning and Melancholia." ${ }^{2}$ Here, he tried to delineate universal propositions on the grief processes, rather than looking for extreme forms of mourning. During the following decades, Eric Lindemann, ${ }^{3}$ John Bowlby, ${ }^{4}$ Colin M. Parkes, ${ }^{5}$ G.L. Engel, ${ }^{6}$ and Beverley Raphael ${ }^{7}$ made important and insightful contributions to various aspects of pathological variants of grief or mourning. The more recent history of a new diagnostic entity related to bereavement or grief began with research by Mardi J. Horowitz, who outlined the very first description of PTSD criteria and symptoms. In 1974, he pointed to a similarity in terms of content between PTSD and grief patients. ${ }^{8}$ Horowitz, Bonanno, and Holen ${ }^{9}$ called this family of failure-to-adapt disorders the "stressresponse syndromes." ${ }^{\prime \prime}$ This concept is becoming increasingly recognized and may appear as a new area of disorders in the $I C D-11$ and the DSM-5.

Horowitz and colleagues ${ }^{9,10}$ suggested that core symptoms of complicated grief are intrusive-preoccupation, denial-avoidance, and failure-to-adapt-the last containing enduring feelings of loneliness or emptiness, difficulties with new intimacy, and keeping possessions of the deceased the same. The Horowitz group established the first operational diagnoses of a bereavement-related disorder that subsequently stimulated much research. In the following years, Holly G. Prigerson became interested in developing reliable and valid diagnostic criteria. Together with her research group, Prigerson developed a widely used questionnaire, the "Inventory of Complicated
Grief" (ICG $\left.{ }^{11}\right)$. For many years, this was considered to be the "gold standard" of complicated grief (CG) research (see below). Over the years, the labels of the condition would change: from pathological to complicated, traumatic, and prolonged grief.

The Horowitz team based their conceptualization of CG on the stress response theory, which views bereavement as a stressful life event. ${ }^{10}$ Horowitz ${ }^{12}$ suggested a general change of the DSM categories, in the sense that PTSD should be removed from the category "Anxiety Disorders," and a new category, "Stress Response Syndromes," should be created. ${ }^{12}$ These Stress Response Syndromes would include psychiatric disorders that are caused by the experience of stress: PTSD, Adjustment Disorder, Acute Stress Disorder, Stress-Induced Psychosomatic Disorder, and Complicated Grief.

Recently, Prigerson, Vanderwerker, and Maciejewski ${ }^{13}$ developed new diagnostic criteria labelled "Prolonged Grief." ${ }^{3,14}$ The authors explain that the term prolonged expresses the nature of the disorder more clearly. Nonetheless, duration is not the main factor of a dysfunctional bereavement. ${ }^{14}$ The Prigerson team distinguished between the core symptoms separation distress (eg, yearning) and traumatic distress, the latter being when sufferers would experience being shocked, dazed, stunned, emotionally numb, or angry.

For a decade these two influential approaches to assess or diagnose PGD remained independent of one another in their undertaken research. Only in 2009 did Prigerson, Horowitz, and other proponents of PGD diagnostic criteria reach a consensus on clinical PGD criteria. ${ }^{13}$ This consensus resulted from a reanalysis of field trial data from the Yale Bereavement Study, which involved 317 participants. These participants were interviewed at baseline and at an average of 6.3 months (SD = 7 months) after the loss. The first follow-up interviews were completed approximately 11 months after the loss, and the second follow-up interviews took place approximately 20 months after the loss. PGD symptoms were assessed using an extended rater version of the Inventory of Complicated Grief-Revised. ${ }^{11}$ Analyses aimed to derive a set of informative, unbiased symptoms allowing for a complete set of "DSM-style" diagnostic criteria. The researchers used an item response method to derive the most informative symptoms, followed by combinatory analysis to identify the most sensitive and specific algorithm for the diagnosis of PGD. 
Before the consensus criteria are outlined in greater detail, the most recent and most influential author and researcher in the area should be introduced. M. Kathy Shear has done commendable work in many areas. In several papers, she investigated the distinction between normal and complicated grief (eg, ref 15). Shear proposed central etiological mechanisms, eg, attachment or other behavioral motivation systems and its biological basis. ${ }^{15,16}$ Most importantly, Shear conducted the first randomized controlled trial on PGD treatment. ${ }^{17}$ The latter was a thoroughly conducted treatment study, which presented an interesting combination of techniques of PTSD therapy as well as other therapy techniques (see below).

\section{The current proposals for diagnosing prolonged grief disorder}

Currently, the consensus criteria by Prigerson, Horowitz, and colleagues, ${ }^{13}$ as well as those proposed by the DSM-5 working group ${ }^{18}$ are as follows.

The set of diagnostic criteria of the consensus group ${ }^{13}$ specifies that a bereaved person with PDG must experience yearning and at least five of nine additional symptoms. These symptoms must persist for at least 6 months after the bereavement and must be associated with functional impairment.

DSM-5 requires that the bereavement occurred a minimum of 12 months previously, while those of Prigerson et al state that a diagnosis should not be made until at least 6 months have elapsed since the death. While Prigerson et al emphasize the possibility of comorbidity with several depression- and anxiety-related disorders, $D S M-5$ focuses on culture-related considerations. Finally, DSM-5 demands specification of degree of trauma associated with grief.

The point at which the psychological state of a mourning person becomes "pathological" or even a disorder has been widely debated. The debate centers around the extent to which CG-now the most used term for this condition-represents a truly unique pathological entity, not only when contrasted with normal grief but also with PTSD or major depression. One easy accessible indicator is to listen to clients or patients. Self-statements such as "I fear I will go crazy if I fully realize the death of my loved one" is very specific to CG but not to depression. ${ }^{19}$

At this point, distinctions between normal grief courses and a bereavement-related disorder need to be discussed. As other authors, Zisook and Shear ${ }^{15}$ have shown, normal or uncomplicated grief shows a broad variability since it is different for every person and for every bereavement, in particular its main affects or cognitions (eg, sadness, despair, loneliness, disbelief, bewilderment), its intensity and duration is highly variable. Here, symptoms range from mild alterations to profound outbursts and dysfunction. However, painful experiences are intermingled with positive feelings, such as joy, peace, and gratitude. For normal grief, it is assumed that grieving individuals are able to move from acute grief states in the early aftermath of a death, to states of integrated or abiding remeniscences where the deceased is more easily called to mind, the reality of the death is acknowledged, and the bereaved person is able to return to enjoyable relationships and activities. Finally, the bereaved person is able to form a new symbolic relationship with the deceased, whereby they are able to accept them back into their lives, as deceased.

Conversely, some bereaved individuals can experience a prolonged or intense form of grief that is associated with substantial impairment to work, health, and social functioning. This state is what Horowitz, Prigerson, Shear, and other researchers call CG, but it is also referred to as unresolved or traumatic grief. In these cases, the bereaved person typically has difficulty in accepting the death, and intense separation and traumatic distress usually last well beyond 6 months. The bereaved find themselves in a repetitive loop of intense yearning and longing, which become the major focus of their lives. They may also believe that their life is over, and that the intense pain that they perceive will never end. Overall, a significant preoccupation with the deceased can develop. On one hand, overinvolvement with activities related to the deceased can often occur, while on the other, excessive avoidance-as demonstrated by patients suffering from PTSD.

\section{Communalities and differences between prolonged grief disorder and post-traumatic stress disorder}

As already outlined, PGD shares some commonalities with the PTSD diagnosis. This is to be expected, if it is assumed that these two clinical conditions belong to stress-response syndromes. Table I gives an overview of similarities and differences between the two. The B-criteria of both disorders address overlapping phenomenological domains: intrusive thoughts and yearning. 


\section{Clinical research}

Whereas intrusive thoughts are defined as painful memories of the trauma, the yearning symptoms are defined as intrusive, unfulfilled wishes that the deceased person be present. Both kinds of symptoms may be defined as permanent memory states. With respect to PTSD, this manifests itself as negative sensory or cognitive-emotional content of the traumatic experience. Meanwhile, in PGD, the permanent memory states are the bittersweet memories of the deceased person and other related experiences, and their subsequent cognitive-emotional appraisals. The common factor here is the duration of these memories. However, the difference lies in the emotional valence of these contents: negative for PTSD and bittersweet (negative and positive, often simultaneously) for PGD.

\begin{tabular}{lcc} 
& PGD & PTSD \\
Core symptom group & Yearning symptoms & Intrusive symptoms \\
\hline 1st additional & Avoidance/numbing & Avoidance/numbing \\
symptom group & symptoms & symptoms \\
\hline 2nd additional & Failure-to-adapt & Hyperarousal \\
symptom group & symptoms & symptoms \\
\hline Minimum duration & More than 6 months & More than 1 month \\
\hline
\end{tabular}

Table I. Communalities and differences of prolonged grief disorder (PGD) and post-traumatic stress disorder (PTSD).

In the current edition of $D S M$, the C-criteria include avoidance and numbing symptoms, and the D-criteria include hyperarousal symptoms. The following PGD criteria correspond to avoidance and numbing: C2 (difficulty accepting the loss), $\mathrm{C} 3$ (avoidance of reminders or avoidance of thoughts, activities, or situations), C4 (Inability to trust/Detachment from others), C7 (Numbness/Absence of emotion), C8 (Feeling that life is empty). In contrast to PTSD there are no hyperarousal symptoms for PGD. The remaining symptoms (C1, C5, C6, C9) may be considered as failure-to-adapt symptoms).

Another difference is the duration criteria in order to diagnose the disorder, which is 1 month for PTSD and 6 months for PGD. This implies that one needs at least 6 months to distinguish between healthy adaptation and maladjustment, which is in keeping with cross-cultural studies on the course of grief.

The implications of the commonalities and differences will be discussed below. Indeed, when the core phenomenological symptoms are similar and a further group of symptoms is identical, this should have implications for therapy.

\section{Assessment instruments and questionnaires}

The assessment of grief or PGD by self-report measures and interviews has produced many forms and solutions. Here we will give a short chronological overview. The Texas Revised Inventory of Grief (TRIG) ${ }^{20}$ is a 21 -item scale designed to measure the extent of unresolved or pathological grief. It relates to two points in time: past (immediately or shortly after the death) and present (the time of data collection). Its first 8 -item subscale measures feelings and actions at the time of the death (ie, the extent to which the death affected emotions, activities, and relationships). The second 13 -item subscale measures present feelings (continuing emotional distress, lack of acceptance, rumination, painful memories). Although the TRIG does not measure PGD, the individual items reflect typical signs of mourning and grief, such as continuing emotional distress, lack of acceptance, rumination, and painful memories. Prigerson et $\mathrm{al}^{11}$ reported a high correlation with the Inventory of Traumatic Grief (see detailed description of instrument below). The authors' claim that parts 1 and 2 over time might indicate different stages of grief resolution, however, has been criticized. ${ }^{21}$ Nevertheless, the TRIG remains a classic scale to measure the impact of a loss. The Hogan Grief Reaction Checklist (HGRC) 22 is a 61item instrument with six subscales: despair, panic behavior, blame and anger, disorganization, detachment, and personal growth. It has been primarily used for assessing grief in parents of deceased children.

In the meantime, the most commonly used assessment tool in the area is the Inventory of Complicated Grief (ICG). It was developed by Prigerson and colleagues ${ }^{11}$ and focuses on symptoms that are distinguishable from symptoms of depression and anxiety (eg, reactions such as preoccupation with thoughts of the deceased, disbelief about the death and nonacceptance of its reality). Moreover, the ICG was designed to distinguish between normal reactions and more pathological forms. The ICG consists of 19 items (eg, "ever since she died it is hard for me to trust people"). Its convergent and discriminant validity yielded excellent results. High ICG values were associated with a lower quality of life. Moreover, scores at 6 months after loss predicted risk of cancer, high blood pressure, heart trouble, smoking, and eating problems 1 to 2 years later. ${ }^{23}$

In an attempt to compare the ICG with Horowitz's concept of PGD, Forstmeier and Maercker ${ }^{24}$ conducted a 
comparative study using a 30-item questionnaire according to the Horowitz model. ${ }^{9}$ They found only a small convergent validity between the two assessments. The authors concluded that the main reasons for this nonconvergence were the number of symptoms or criteria that had to be present in order to diagnose PGD.

For the most recent consensus criteria on PGD (see above $^{13}$ ), no validated clinical assessment has so far been published. However, a short screening scale, the PG-13, has been developed by Prigerson's group ${ }^{14}$ and it has already been used in several studies (eg, ref 25). It is a promising tool to investigate PGD in various populations and has the advantage of being short and comprehensive.

\section{Epidemiology}

To date, there are no methodologically sound studies that provide information about the prevalence of complicated grief in the general population. However, two issues are of particular interest. First, the general prevalence (eg, 1-year prevalence). The second is the conditional probability: the proportion of bereaved persons who develop PGD. Various authors have reported probabilities of around $10 \%,{ }^{13,26}$ implying that almost one third of all bereaved develop PGD.

So far, the only representative epidemiological studies are on elderly samples, including persons 60 to 94 years old. ${ }^{27,28}$ In the Swiss population within this age group, $4.2 \%$ of the 712 participants were diagnosed with PGD based on the previous Horowitz criteria. ${ }^{28}$ Women were diagnosed more often: $5.8 \%$ of all women, against $2.1 \%$ of men. The conditional probability was $16 \%$, meaning that one out of six had the disorder. Patients with PGD had 1.9 (SD 1.0) comorbid psychiatric disorders with subthreshold depression as the most frequent comorbid condition. Further, 17\% were receiving psychopharmacological treatment, but not one PGD patient was in therapy.

Newson and colleagues ${ }^{27}$ recently undertook a study of 5741 older adults, based within the Rotterdam Study, using the 17-item Inventory of Complicated Grief. ${ }^{11}$ This study is one of the first estimates provided for CG in the general population using clinical interviews. They found a prevalence of $4.8 \%$ for complicated grief disorder within the general population. Overall, 1089 participants were found to be currently experiencing grief. Of these, 277 were diagnosed with CG, which equals a conditional prevalence of $25.4 \%$ in the population. Interestingly, while the authors report inflated rates for anxiety and depression in people with CG, comorbidity was not found for the vast majority of participants. As such, CG may be considered to be both a distinct disorder, but also as existing along a continuum, rather than as a clear taxon. ${ }^{27}$ The highest prevalence rate was found to be in the 75 - to 85 -year-old age-group, with a rate of $7 \%$, as compared to $4.8 \%$ for older adults overall.

In Japan, an epidemiological screening study was recently conducted ${ }^{29}$ using a five-item scale that evaluated intrusions, avoidance, estrangement from others, trouble accepting the death, and interference of grief in daily life. Participants were 40 to 79 years old; however, the study included only participants who reported bereavement, which may be a bias because there are people in the general population who do not report bereavement at all. The authors found what can be considered a conditional probability of $2.4 \%$ in that population. Both studies converged, despite methodological differences, on the finding that PGD patients are few in the general population. Furthermore, their number is age-dependent. Indeed, for biological reasons, older people are more likely to be affected by bereavement involving persons in their social network.

\section{Further threads in prolonged grief disorder research}

Proper research on a (new) psychological disorder must not focus on diagnostics, assessment, prevention, and treatment alone. While these aspects of research are important, we argue that a core understanding and appreciation of the disorder must also be promoted. It should be noted that the recent edition of the Handbook of Bereavement: Research and Practice by M. S. Stroebe and colleagues ${ }^{30}$ provides a comprehensive collection of the major theories and impulses on these aspects.

Stroebe and Shut ${ }^{31}$ proposed a systematic model of grief in general, the dual-process model in concordance with Rubin's ${ }^{32}$ earlier two-track model of bereavement. They proposed that a loss-oriented process, whereby self-confrontation or avoidance can provide alleviation, allowing an individual to rebuild their life, has to be distinguished from a restoration-oriented process, where the individual may cope with the loss by engaging in new relationships and tasks. According to the model, these two processes represent individual differences in terms of alternatives or individual styles used by different peo- 


\section{Clinical research}

ple but may, however, also occur within the same person as an oscillating process. Stroebe and Shut propose that both are important for eventual adaptation to the loss, and that oscillation between the two enables the occurrence of a balanced recovery. This oscillation between phases of intrusion and phases of avoidance is supported by Horowitz's $\mathrm{s}^{33}$ model of working, in that it is a necessary process for adaptation.

Interestingly, the dual-process model only consists of psychological factors, whereas the most influential models of PTSD emphasise basic memory processes and are more closely related to neuroscience. Admittedly, there are few approaches in PGD research which involve neurobiology, for example, genetic factors ${ }^{34}$ or brain activity patterns. ${ }^{35}$ A good fit can be found between the dual-process mode $^{36}$ and deepened investigation of risk factors, such as has been shown for cognitive or social-affective changes after bereavement. One example is that loss-oriented processes are typical socioemotional reactions that accompany the feeling of injustice or anger associated with loss and that may vary in degree from moderate to exaggerated. Anger over the circumstances of the death of a loved one could lead to more severe grief, especially when the death is perceived as unjust, such as in the case of the death of a child. Again, this highlights that PTSD and PGD may indeed be closely related. From bereaved parents' beliefs that fate is unjust to the anger held by post-traumatic victims of crime ${ }^{36}$ studies have found that such negativistic attributions lead to worsening psychopathological outcomes.

For restoration-oriented processes, the differences between PGD and PTSD are more apparent. In PTSD, people typically fail to assimilate their experiences and have prevailing perceptions of their fundamental beliefs, like avoiding driving after experiencing a road-traffic accident, or holding unrealistic beliefs about the likelihood of physical altercations and severely restricting one's social life after a serious physical assault. The consequence of PTSD is a persisting inconsistency warningsignal, accompanied by strong negative emotions which result in the psychological system being constantly preoccupied with detecting dangerous inconsistencies. ${ }^{37} \mathrm{In}$ contrast, in PGD the predominant feeling is not threat but loss-related distress. The persisting inconsistency concerns lack of affiliation. Znoj and Grawe ${ }^{38}$ have suggested that striving for consistency between prevailing experiences and expectations form the basis for patients' ongoing failure to adapt.

\section{Preventive and treatment approaches}

In this section, available psychotherapeutic and psychopharmacological interventions will be discussed.

Zisook and Shear ${ }^{15}$ summarize the pharmacological knowledge on PGD treatment. There are six published studies on bereavement-related depression demonstrating the efficacy and safety of a variety of antidepressant medications (escitalopram, ${ }^{39}$ desipramine, ${ }^{40}$ sertraline or nortriptyline, ${ }^{41}$ nortriptyline ${ }^{42}$ nortriptyline, ${ }^{43}$ bupropion $\left.^{44}\right)$. In each of these studies, grief intensity diminished along with amelioration of depressive symptoms, although improvement in grief was not as robust as relief of depression. No single antidepressant medication is currently designated the "best" treatment for bereavement-related depression.

Inquiring about patient preferences and past personal successes or failures with various antidepressant trials can help guide a rational choice in medication. If the depressive episode is relatively mild and not associated with suicidal risk or melancholic features, support and watchful waiting might be an appropriate initial choice. On the other hand, the more autonomous and severe the symptoms, the more antidepressant medications should enter the treatment equations. For severe or highly comorbid episodes, or where medication has been unsuccessful, combination treatment with multiple medications in addition to targeted psychotherapy may be needed.

A recent meta-analysis sheds light on the empirical status both of available therapeutic and preventative treatment for CG. ${ }^{45}$ They found nine studies which examined preventive grief interventions. Three of these studies reported moderately positive results with regard to CG, of which two offered a cognitive-behavioral oriented preventive intervention. Five studies examined treatment grief interventions. Positive results with respect to $\mathrm{CG}$ were reported in four of these studies. All of these four treatment interventions employed cognitive-behavioral techniques.

The results from preventive grief intervention studies provide inconsistent support for their effectiveness. Treatment interventions, on the other hand, appear to be efficacious in the short-term and long-term alleviation of CG symptoms. Contrary to preventive interventions, the positive effect of treatment interventions increases significantly over time. 
Interestingly, while treatment approaches are informed by the work within the PTSD field, current preventive approaches are mostly not. Only a few prevention programmes have proven effective, and many must be considered ineffective. ${ }^{30}$ Not every well-intentioned preventive approach meets with success.

The first prevention study we report had no beneficial effects. De Groot et $\mathrm{al}^{46}$ conducted a prevention program for a specific group of bereaved: survivors of a relative who had committed suicide. The prevalence of PGD is considered to be high in this population. Specialized nurses visited patients at home. The program consisted of four 2-hour sessions, with 2 to 3 weeks between each session; most of the time they were family sessions. The preventive program offered a range of styles of intervention treatments. A total of 122 first-degree relatives of 70 people who had committed suicide took part (mean age 44 years, SD 17 years). No significant reduction effect was found for the Inventory of Traumatic Grief. ${ }^{11}$

Conversely, Wagner and Maercker ${ }^{47}$ found effective forms of prevention. They conducted a structured preventive program on the Internet within the bereavement counseling center of a Catholic diocese in Germany. It consisted of a 3-week manualized program, incorporating narrative, cognitive-behavioral, and family-based treatment strategies. This pilot study, which did not contain a control group, investigated 35 bereaved individuals (mean age 42 years, SD 9 years) who had experienced a loss within the last year. The sample can be regarded as a highly stressed one because $57 \%$ had lost a child and $21 \%$ a partner. Overall, $82 \%$ were unexpected deaths. Participants in the preventive program reached a significant reduction in symptoms of PGD and depression. For example, PGD symptoms assessed by the Horowitz criteria were reduced by an effect size of $\mathrm{d}=2.0$, whereas depression (HADS) was reduced by $\mathrm{d}=.44 .{ }^{47}$ It can be concluded that some or all modules of this program were helpful, and further disentangling studies must clarify this.

In the following, current treatment approaches to PGD will be outlined. M. Katherine Shear's approach to treating PGD has become widely recognized. ${ }^{17}$ Demonstrating the similarities between PGD and PTSD, this approach was essentially informed by the imaginal and in vivo exposure techniques used for PTSD. The confrontational technique of "revisiting" the deceased loved one is utilized. Here, the latter stages of "normal grief" are used as a model of recovery, whereby the bereaved can redevelop a connection with the deceased. Similar to Foa's ${ }^{48}$ prolonged exposure therapy of traumatic memories, the therapist asks the patient to envisage painful memories as part of the healing process. This stage involves the therapist recording the patient's telling the story of the deceased's death, and the recording is listened to by the patient at home. Overall, Shear's complicated grief treatment has proved successful, and is broadly utilized.

Boelen, Keijser, van den Hout, and van den Bout ${ }^{49}$ conducted a study, using a modified form of such exposurebased treatment similar to the work of Shear. They examine different sequences of exposure and cognitive restructuring. Exposure began with the writing of distressing memories and included imaginal exposure during the sessions. Cognitive restructuring (CR) focused on individual dysfunctional thoughts (eg, guilt, anger). The evaluation was made halfway through therapy. The exposure phase that followed brought more improvement than the $\mathrm{CR}$ phase. Conducting the exposure first followed by CR, yielded the best results.

Finally, an alternative to the more standard exposure treatment for PGD should be mentioned. This involves a Web-based approach for eligible patients. ${ }^{50}$ Demonstrating the association between PGD and PTSD, this approach also begins with a technique of self-confrontation similar to that used in Internet-based therapy of PTSD. ${ }^{51}$ This consists of a written assignment. This is followed by a new letter in which patients write about the circumstances of the bereavement, and how they thought and felt at the time. Finally, patients are asked to write a supportive letter to a friend who finds him- or herself in exactly the same situation. A further example of mirroring normal grief, the therapist facilitates the patient in establishing rituals or activities to commemorate the deceased. Within 10 weeks, patients write a total of 10 assignments upon which they receive individual feedback from their therapist via e-mail, within one workday.

In an RCT with a waitlist control condition and an 18month follow-up condition, the effect sizes were promis-

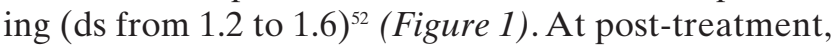
$81 \%$ were healthy (ie, below the clinical threshold), compared with $33 \%$ in the control group. Interestingly, $73 \%$ said they had not missed face-to-face contact with their therapist (missed: 20\%; don't know: 8\%). 


\section{Clinical research}

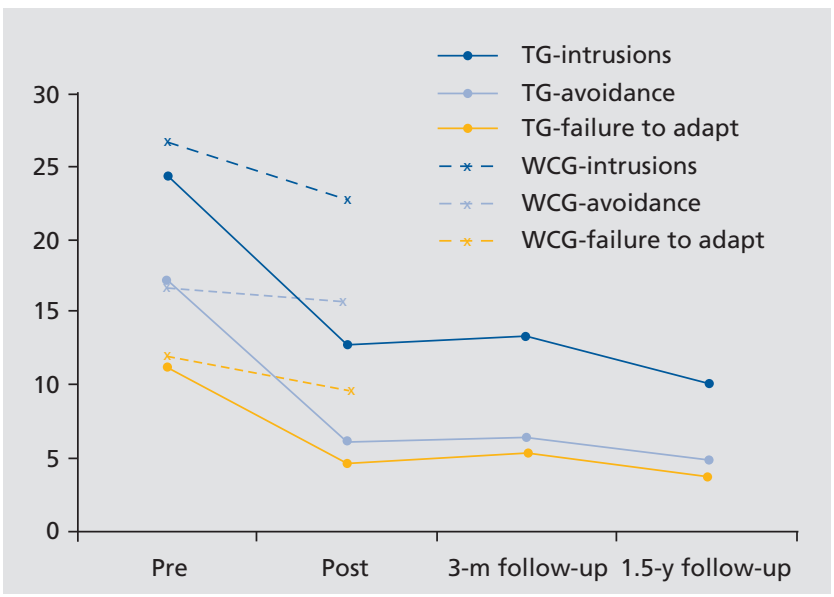

Figure 1. Results of a randomized treatment trial of Web-based cognitive-behavioral therapy of PGD. ${ }^{46,49}$ Scores [0-30] are described in refs 46 and 49 . TG, treatment group; WCG, waitlist control group; $3 \mathrm{~m}, 3$ months; $1.5 \mathrm{y}, 1.5$ years

A similar Web-based intervention for CGD is an ehealth innovation by Botella and colleagues..$^{53}$ This team utilized a virtual reality program called "EMMA's World." This program provides different tools to deal

\section{REFERENCES}

1. Maercker A, Znoj H. The younger sibling of PTSD: similarities and differences between complicated grief and posttraumatic stress disorder. Eur J Psychotraumatol. 2010;1:55-58.

2. Freud S. Mourning and melancholia. In: The Standard Edition of the Complete Psychological Works of Sigmund Freud. Vol 14. London, UK: Hogarth; 1917.

3. Lindemann E. Symptomatology and management of acute grief. Am J Psychiatry. 1944; 101:141-148.

4. Bowlby J. Grief and mourning in infancy and early childhood. Psychoanal Stud Child. 1960;15:9-52.

5. Parkes CM. Bereavement: Studies of Grief in Adult Life. New York, NY: International Universities Press; 1972.

6. Engel GL. Is grief a disease? A challenge for medical research. Psychosom Med. 1961;23:18-22.

7. Raphael B. The Anatomy of Bereavement. New York, NY: Basic Books; 1985.

8. Horowitz M. Stress response syndromes. Arch Gen Psychiatry. 1974; 31:768-781.

9. Horowitz MJ, Bonnano GA, Holen A. Pathological grief: diagnosis and explanation. Psychosom Med. 1993;55:260-273.

10. Horowitz MJ, Siegel B, Holen A, Bonanno GA, Milbrath C, Stinson CH. Diagnostic criteria for complicated grief disorder. Am J Psychiatry. 1997;154:904-910.

11. Prigerson HG, Maciejewski PK, Newsom J, et al. The inventory of complicated grief: a scale to measure certain maladaptive symptoms of loss. Psychiatr Res. 1995; 59:65-79.

12. Horowitz M. Meditating on complicated grief disorder as a diagnosis. Omega. 2006;52:87-89.

13. Prigerson HG, Horowitz MJ, Jacobs SC, et al. Prolonged grief disorder: psychometric validation of criteria proposed for DSM-V and ICD-11. PLOS Med. 2009;6:e1000121. with negative emotions (eg, sadness, anger, anxiety) and is complemented by self-exposure to painful memories about the loss. The single case was successfully treated with the effects remaining stable up to the 12-month follow-up.

\section{Outlook}

In conclusion, this paper has shown complicated or prolonged grief disorder to be closely related to PTSD, and tried to illustrate this view. There are both characteristic similarities and differences between this pair of presentations. Effective preventive and treatment approaches are already available, and most of them have been deduced from PTSD therapy rationales, demonstrating the similarities between PTSD and PGD. However, since contemporary theoretic contributions to, and models of, PGD are still relatively scarce, many more researchers and clinicians are invited to contribute to a better understanding of the humane and clinical phenomena of bereavement, grief, and how to overcome them.

14. Prigerson HG, Vanderwerker LC, Maciejewski PK. A case for the inclusion of prolonged grief disorder in DSM-V. In: Stroebe M, Hansson R, Schut $\mathrm{H}$, Stroebe W, eds. Handbook of Bereavement Research and Practice: 21st Century Perspectives. Washington, DC: APA; 2008:165-186.

15. Zisook S, Shear K. Grief and bereavement: what psychiatrists need to know. World Psychiatry. 2009;8:67-74.

16. Shear K, Shair H. Attachment, loss, and complicated grief. Dev Psychobiol. 2005;47:253-267.

17. Shear K, Frank E, Houck PR, Reynolds CF. Treatment of complicated grief: a randomized controlled trial. JAMA. 2005;293:2601-2608.

18. American Psychiatric Association (2011). DSM-5 Development. G 06 Adjustment Disorders. Available at: http://www.dsm5.org/proposedrevision/pages/ proposedrevision.aspx?rid=367. Accessed 26 Oct 2011.

19. Boelen PA, Keijser J, van den Hout MA, van den Bout J. Treatment of complicated grief: A comparison between cognitive-behavioral therapy and supportive counseling. J Consult Clin Psychol. 2007;75:277-284.

20. Faschingbauer TR. Texas Revised Inventory of Grief Manual. Houston, TX: Honeycomb Publishing; 1981.

21. Neimeyer RA, Hogan NS. Quantitative or qualitative? Measurement issues in the study of grief. In: Stroebe MS, Hanson RO, Stroebe W, Schut H, eds. Handbook of Bereavement. Washington, DC: American Psychological Press; 2001:133-161.

22. Hogan NS, Greenfield DB, Schmidt LA. Development and validation of the Hogan Grief Reaction Checklist. Death Studies. 2001;25:1-32.

23. Prigerson HG, Bierhals AJ, Kasl SV, et al. Traumatic grief as a risk factor for mental and physical morbidity. Am J Psychiatry. 1997;154:616-623.

24. Forstmeier S, Maercker A. Comparison of two diagnostic systems for complicated grief. J Affect Disord. 2007;99:203-211.

25. Schaal S, Jacob N, Dusinizemungu J-P, Elbert T. Rates and risks for prolonged grief disorder in a sample of orphaned and widowed genocide survivors. BMC Psychiatry. 2010;10:1-9.

26. Middleton $W$, Raphael B, Burnett $P$, Martinek N. A longitudinal study comparing bereavement phenomena in recently bereaved spouses, adult children and parents. Aust N Z J Psychiatry. 1998;32:235-241. 


\section{Consideraciones diagnósticas y clínicas del trastorno por duelo prolongado}

Esta revisión se centra en las semejanzas y diferencias entre el trastorno por duelo prolongado (TDP) y el trastorno por estrés postraumático (TEPT). Se destaca cómo una interpretación relacionada con el TEPT ayuda a la investigación y al manejo clínico del TDP. Desde hace mucho tiempo se ha supuesto que el duelo es una respuesta natural a la pérdida, y como un estrés psicológico y fisiológico grave se lo ha considerado el resultado potencial de un estrés extremo o traumático. El TEPT se incluyó inicialmente en el DSM-III en 1980. A mediados de los años 1980 la primera investigación sistemática se orientó a definir si existe una forma extrema o patológica del duelo. Entretanto se ha acumulado bastante literatura relacionada con la investigación sobre duelo complicado, traumático o prolongado. En este artículo se revisa esta literatura con las siguientes preguntas: ¿Es posible distinguir el duelo normal del anormal? ¿Cuáles son las presentaciones clínicas del TDP y cómo se diferencian del TEPT? Para finalizar se presentan las aproximaciones $y$ herramientas disponibles para el diagnóstico, la prevención y el tratamiento.

\section{Considérations et diagnostiques cliniques dans le deuil prolongé pathologique}

Cet article s'intéresse aux ressemblances et différences entre le deuil prolongé pathologique (DPP) et l'état de stress post-traumatique (ESPT). La façon dont la compréhension de l'ESPT aide à la recherche et à la prise en charge clinique du DPP y est soulignée. La douleur morale a longtemps été considérée comme une réponse naturelle à la perte d'un être cher, de même qu'une réaction de stress sévère psychologique et physiologique était considérée comme une évolution potentielle d'un facteur de stress extrême ou traumatique. L'ESPT a été inclus dans le DSM-III en 1980. Au milieu des années 80 eut lieu la première recherche systématique pour savoir s'il existait une forme extrême ou pathologique de deuil. Dans l'intervalle, la littérature s'est enrichie sur le deuil prolongé, traumatique ou compliqué ; nous l'analysons ici en posant les questions suivantes : est-il possible de distinguer la douleur morale normale de la douleur morale anormale après la perte d'un être cher? Comment se présente cliniquement le DPP et comment le comparer à l'ESPT ? Et enfin, nous concluons en présentant les outils existants et les approches thérapeutiques, préventives et diagnostiques.
27. Newson RS, Boelen PA, Hek K, Hofman A, Tiemeier H. The prevalence and characteristics of complicated grief in older adults. J Affect Disord. 2011;132:231-238.

28. Maercker A, Forstmeier S, Enzler A, et al. Adjustment disorders, PTSD and depressive disorders in old age: findings from a community survey. Comp Psychiatry. 2008;49:113-120.

29. Fujisawa D, Miyashita M, Nakajima S, et al. Prevalence and determinants of complicated grief in general population. J Affect Disord. 2010;127:352-358. 30. Stroebe MS, Hannson RO, Stroebe W, Schut H, eds. Handbook of Bereavement Research and Practice. Washington DC: American Psychological Association Press; 2008.

31. Stroebe MS, Schut H. The dual process model of coping with bereavement: rationale and description. Death Stud. 1999;23:197-224.

32. Rubin S. Adult child loss and the two-track model of bereavement. Omega. 1992;24:183-202.

33. Horowitz M. Stress Response Syndromes. New York, NY: Jason Aronson; 1978. 34. Kersting A, Kroker K, Horstmann J, et al. Association of MAO-A variant with complicated grief in major depression. Neuropsychobiology. 2007;56:191-196. 35. O'Connor MF, Wellisch DK, Stanton AL, Eisenberger NI, Irwin MR, Lieberman MD. Craving love? Enduring grief activates brain's reward center. Neuroimage. 2008;42:969-972.

36. Orth U, Maercker A. Posttraumatic anger in crime victims: directed at the perpetrator and at the self. J Traum Stress. 2009;22:158-161.

37. Ehlers A, Clark DM. A cognitive model of posttraumatic stress disorder. Behav Res Ther. 2000;38:319-345.

38. Znoj HJ, Grawe K. The control of unwanted states and psychological health: consistency safeguards. In: Grob A, Walter P, eds. Control of Human Behaviour, Mental Processes and Awareness. New York, NY: Lawrence Erlbaum; 2000:263-282.
39. Hensley PL, Slonimski CK, Uhlenhuth EH. Escitalopram: an open-label study of bereavement-related depression and grief. J Affect Disord. 2009;113:142-149.

40. Jacobs SC, Nelson JC, Zisook S. Treating depressions of bereavement with antidepressants. A pilot study. Psychiatr Clin North Am. 1987;10:501510 .

41. Oakley F, Khin NA, Parks R, et al. Improvement in activities of daily living in elderly following treatment for post-bereavement depression. Acta Psychiatr Scand. 2002;105:231-234.

42. Pasternak RE, Reynolds CF 3rd, Schlernitzauer M, et al. Acute open trial nortriptyline therapy of bereavement-related depression in late life. J Clin Psychiatry. 1991;52:307-310.

43. Reynolds CF, Miller MD, Pasternak RE, et al. Treatment of bereavementrelated major depressive episodes in later life: a controlled study of acute and continuation treatment with nortriptyline and interpersonal therapy. Am J Psychiatry. 1999, 156:202-208.

44. Zisook S, Shuchter SR, Pedrelli $P$, et al. Bupropion sustained release for bereavement: results of an open trial. J Clin Psychiatry. 2001;62:227230.

45. Wittouck C, van Autreve S, de Jaegere E, Portzky G, van Heeringen $\mathrm{K}$. The prevention and treatment of complicated grief: a meta-analysis. Clin Psychol Rev. 2001;31:69-78.

46. De Groot M, de Keijser J, Neeleman J, Kerkhof A, et al. Cognitive behaviour therapy to prevent complicated grief among relatives and spouses bereaved by suicide: cluster randomized controlled trial. BMJ. 2007;334:994-999.

47. Wagner B, Maercker A. An internet-based preventive intervention (CBT) for complicated grief: a pilot study. Psicologia Applicata alla Medicina del Lavoro e della Riabilitazione. 2008;30:B43-B47. 


\section{Clinical research}

48. Foa EB, Hembree EA, Rothbaum BO. Prolonged Exposure Therapy for PTSD: Emotional Processing of Traumatic Experiences, Therapist Guide. Oxford, UK Oxford University Press; 2007.

49. Boelen PA, van den Bout J, van den Hout MA. A cognitive-behavioral conceptualization of complicated grief. Clin Psychol: Sci Pract. 2006;13:109-

128.

50. Wagner B, Knaevelsrud C, Maercker A. Internet-based cognitive-behavioral therapy for complicated grief: a randomized controlled trial. Death Stud. 2006;30:429-453.
51. Lange A, Rietdijk D, Hudcovicova M, van de Ven JP, et al. Interapy: a controlled randomized trial of the standardized treatment of posttraumatic stress through the internet. J Consult Clin Psychology. 2003;71:901-909.

52. Wagner B, Maercker A. A 1.5 year follow-up of an internet-based intervention of complicated grief. J Traum Stress. 2007;20:625-629.

53. Botella C, Osma J, Garcia Palacios A, Guillen V, Banos R. Treatment of complicated grief using virtual reality: a case report. Death Stud. 2008;32:674692. 